\title{
Clinicopathological significance and prognostic role of P-STAT3 in patients with hepatocellular carcinoma
}

This article was published in the following Dove Press journal: OncoTargets and Therapy

\author{
Chaojie Liang* \\ Yingchen $\mathrm{Xu}^{*}$ \\ Hua $\mathrm{Ge}$ \\ Guangming Li \\ jixiang Wu
}

Department of General Surgery, Beijing Tongren Hospital, Capital Medical University, Beijing, People's Republic of China

*These authors contributed equally to this work
Correspondence: Guangming Li; Jixiang Wu

Department of General Surgery, Beijing Tongren Hospital, Capital Medical University, No 2, Chongwenmennei Street, Dongcheng, Beijing I00730, People's Republic of China $\mathrm{Tel}+86$ I 35 0 I I 2244 ; $+8613801015118$ Email liguangming2016@126.com; trwujixiang2016@I26.com
Background and aim: Constitutive activation of STAT3 through its phosphorylation (p-STAT3) plays a key role in the development and progression of various cancers. However, the relationship between p-STAT3 expression and the clinicopathological features and prognostic value in patients with hepatocellular carcinoma (HCC) remains controversial. We conducted a meta-analysis to evaluate the role of p-STAT3 in HCC.

Methods: The PubMed, Cochrane Library, Web of Science, EMBASE, Chinese CNKI, and Chinese Wanfang databases were searched using the appropriate terms to find the relevant studies on p-STAT3 and HCC. The relationship between p-STAT3 expression and clinicopathological characteristics and prognostic value was established. Pool odds ratios (ORs) and hazard ratios (HRs) with 95\% CIs were calculated using the STATA 14.2 software.

Results: The eight articles included in this meta-analysis comprised 752 patients. Expression of p-STAT3 was associated with incidence, age, liver cirrhosis, tumor size, vascular invasion, and TNM stage of HCC, but it was not related to gender, alpha-fetoprotein (AFP), hepatitis B surface antigen (HBsAg), number of tumors, and tumor differentiation. Additionally, the expression of p-STAT3 was related to a poor 3- and 5-year overall survival rate and disease-free survival rate.

Conclusion: Expression of p-STAT3 was associated with the incidence, age, liver cirrhosis, tumor size, vascular invasion, and TNM stage. Thus, p-STAT3 can be a reliable prognostic biomarker for HCC. Further high-quality studies with larger numbers of patients are needed.

Keywords: p-STAT3, hepatocellular carcinoma, prognosis, meta-analysis

\section{Background}

Hepatocellular carcinoma (HCC) is prone to lead to intrahepatic metastasis, and the prognosis is poor. More than half of the 660,000 new cases of HCC worldwide each year occur in China. ${ }^{1,2}$ The effective method for the treatment of HCC is a comprehensive treatment based on surgical resection. However, occult onset of HCC can occur and make it difficult to diagnose in the early stage, which leads to many patients with HCC being diagnosed in the middle or late stage. As a result, only $20 \%-25 \%$ of patients with liver cancer are amenable to surgery and the surgical resection rate is very low. In addition, postoperative recurrence and metastasis are common, so the long-term survival rate of patients with HCC remains low. ${ }^{3-5}$ Recently, studies on the mechanisms of recurrence and metastasis of liver cancer at the molecular level have been reported. Nevertheless, a better understanding of the pathogenesis of HCC is needed for the early prediction of its occurrence and prognosis. Thus, the identification of reliable biomarkers for HCC would be valuable. 
Recently, multiple studies have shown that STAT3, an important member of the STAT protein family, is involved in the development and progression of tumors. The constitutive activation of STAT3 through its phosphorylation is thought to be involved in the development, invasion, and metastasis of malignant tumors. ${ }^{6}$ Sustained levels of phosphorylated STAT3 (p-STAT3) have been found in gastric cancer, ${ }^{7}$ pancreatic cancer, ${ }^{8}$ prostate cancer, ${ }^{9}$ breast cancer, ${ }^{10}$ colorectal cancer, ${ }^{11}$ melanoma, ${ }^{12}$ and other malignant tumors. In addition, p-STAT3 has been recognized as an oncoprotein. In particular, p-STAT3 expression has been found to be associated with clinicopathological characteristics and prognosis of patients with HCC, but controversy remains. For instance, $\mathrm{Wu}$ et $\mathrm{al}^{13}$ indicated that the expression of p-STAT3 is only related to TNM stage but not to other aspects including age, gender, and cirrhosis. Zhang et $\mathrm{al}^{14}$ reported associations of p-STAT3 expression with TNM stage and metastasis. Mano et $\mathrm{al}^{15}$ found that $\mathrm{p}$-STAT3 expression was correlated with tumor size, level of alpha-fetoprotein (AFP), and intrahepatic metastasis, but not with tumor differentiation or vascular invasion. Yang et al ${ }^{16}$ found that p-STAT3 expression was associated with intratumor microvessel density in HCC and p-STAT3 was a significant predictor of overall survival (OS) of patients with $\mathrm{HCC}(P=0.036)$.

Two meta-analyses assessed the relationship between STAT3 and prognosis of digestive or various solid tumors. One study ${ }^{17}$ reported that STAT3 expression suggested a poor 3- and 5-year OS rate in solid tumors. However, this meta-analysis did not assess the relationship between p-STAT3 specifically and prognosis and instead included data of p-STAT3 and STAT3 combined. Moreover, there were little data on the association of p-STAT3 with the clinicopathological features of HCC. The other study ${ }^{18}$ explored the relationship between p-STAT3 expression and prognosis of patients with digestive tumors. In this metaanalysis, there were few articles for HCC and no data were included on the correlation between p-STAT3 expression and the 3- and 5-year survival and clinicopathological features of patients with HCC.

These deficiencies prompted the present meta-analysis so as to more thoroughly evaluate the relationship between the expression of p-STAT3 and the clinicopathological features and prognosis of patients with HCC.

\section{Methods}

\section{Search strategy and study selection}

The PubMed, Cochrane Library, Web of Science, EMBASE, Chinese CNKI, and Chinese Wanfang databases were searched up to September 15, 2017, with no limit on the earlier date. The keywords used to perform the search were "p-STAT3" or "phosphorylated signal transducer and activator of transcription 3" and "hepatocellular carcinoma" or "hepatic tumor" or "liver tumor" or "hepatic cancer" or "liver cancer" or "HCC."

The inclusion criteria for studies on HCC and p-STAT3 were as follows: 1) the expression of p-STAT3 in patients with HCC was measured by immunohistochemistry (IHC) analysis; 2) the results included the survival information (OS and disease-free survival [DFS] rates) and clinicopathological characteristics; 3) hazard ratios (HRs) for OS or DFS can be calculated for the survival curves; and 4) in case of repeated studies, the most recent report is included in the meta-analysis.

The exclusion criteria for studies were as follows: 1) case reports, reviews, editorials, letters, conference abstracts, or animal trials and 2) repeated studies based on the same databases.

\section{Data extraction and quality assessment}

All eligible articles were independently screened in the same way by two independent reviewers (CJ Liang and YC Xu). The following data were extracted from eligible studies: first author, publication year, country or region, case numbers, clinicopathological characteristics, 3- and 5-year OS rates, and DFS rate (Table 1). The Newcastle-Ottawa Scale (NOS) criteria were used to assess the quality of the studies. A study was considered to be a low-quality or high-quality study when the NOS score was $<6$ or $\geq 6$, respectively.

\section{Statistical analyses}

The STATA 14.2 (StataCorp LP, College Station, TX, USA) and Engauge Digitizer 10.0 software were used to calculate all statistical data or extract the survival data from KaplanMeier curves. Pooled odds ratios (ORs) were used to assess the relationship between p-STAT3 expression and clinicopathological features (gender [male vs female], age [ $>50$ vs $\leq 50$ years], hepatitis B surface antigen [HbsAg] [yes vs no], AFP [ $>400$ vs $\leq 400$ ], liver cirrhosis [yes vs no], tumor size [ $\leq 5 \mathrm{vs}>5 \mathrm{~cm}$ ], vascular invasion [yes vs no], number of tumors [single vs multiple], tumor differentiation [low vs high + moderate], and TNM stage [I + II vs III + IV]). Pooled HR with 95\% CI was used to evaluate the association between p-STAT3 expression and 3- and 5-year OS and DFS. Heterogeneity was assessed by the $I^{2}$ test and $Q$ test if the $I^{2}<50 \%$ fixed-effects model was used, otherwise the random-effects model was chosen. Funnel plots and Egger's tests were used to assess the potential publication bias. The source of heterogeneity was determined by sensitivity 
and subgroup analyses. If the pooled estimated OR or HR (95\% CI) did not overlap 1, the effect of the expression of p-STAT3 on the clinicopathological features and survival was considered significant.

\section{Results}

\section{Identification of eligible studies, study characteristics, and quality assessment}

A total of 780 potentially relevant studies were selected from the PubMed, Web of Science, Cochrane Library, EMBASE, CNKI, and Chinese Wanfang databases. Duplicated studies, non-HCC studies and nonoriginal articles, comprising 717 articles, were excluded (Figure 1). The remaining 63 articles were further evaluated by reading the abstracts, of which 28 articles were excluded as they were non-p-STAT3-related human studies or did not analyze tumor tissues. The remaining 35 studies were assessed by reading the full text. Of them, 27 studies were excluded because of lack of clinicopathological data. Ultimately, eight $^{13-16,19-22}$ eligible studies involving 752 patients with HCC were included in this meta-analysis. The studies were published between 2007 and 2014, and the sample size ranged from 68 to 138 patients. Six studies were from mainland China, one study was from Japan, and one study was from Taiwan. Five of these studies were published in English, and the others were published in Chinese (Table 1). All eight studies were high quality.

\section{Association between p-STAT3 in HCC and clinicopathological features}

The association between p-STAT3 expression and clinicopathological features of patients with HCC was evaluated. As shown in Table 2 and Figure 2A-K, p-STAT3 was overexpressed in HCC tissue compared to adjacent nontumor tissue $\left(\mathrm{OR}=6.27,95 \% \mathrm{CI}=2.85,13.79, P=0.000, I^{2}=76.5 \%\right.$, random effect) and p-STAT3 expression was associated with age $\left(\mathrm{OR}=1.45,95 \% \mathrm{CI}=1.01,1.49, P=0.044, I^{2}=0\right.$, fixed effect), liver cirrhosis $(\mathrm{OR}=1.56,95 \% \mathrm{CI}=1.01$, 2.43, $P=0.046, I^{2}=0$, fixed effect), tumor size $(\mathrm{OR}=0.56$, $95 \% \mathrm{CI}=0.40,0.78, P=0.001, P^{2}=45.2 \%$, fixed effect), vascular invasion $(\mathrm{OR}=3.43,95 \% \mathrm{CI}=2.13,5.52, P=0.000$, $I^{2}=34.2 \%$, fixed effect), and TNM stage (OR $=0.36,95 \%$ $\mathrm{CI}=0.19,0.70, P=0.042, I^{2}=66.1 \%$, random effect $)$. However, p-STAT3 expression was not significantly related to gender (OR $=0.91,95 \% \mathrm{CI}=0.63,1.31, P=0.618, I^{2}=0$, fixed effect $)$, HBsAg $\left(\mathrm{OR}=1.11,95 \% \mathrm{CI}=0.75,1.65, P=0.597, I^{2}=0\right.$, fixed effect $)$, AFP $\left(\mathrm{OR}=1.40,95 \% \mathrm{CI}=0.92,2.14, P=0.121, I^{2}=0\right.$, fixed effect), number of tumors $(\mathrm{OR}=0.64,95 \% \mathrm{CI}=0.35$, $1.18, P=0.155, I^{2}=0$, fixed effect), and tumor differentiation
$\left(\mathrm{OR}=1.81,95 \% \mathrm{CI}=0.79,4.15, P=0.161, I^{2}=69.3 \%\right.$, random effect). The results of the subgroups analysis based on p-STAT3 expression, tumor differentiation, and TNM stage by sample size and NOS score are presented in Table 3. p-STAT3 was overexpressed in studies with a small sample size $(\mathrm{n} \leq 100, \mathrm{OR}=7.70,95 \% \mathrm{CI}=2.82,21.00, P=0.003$, $I^{2}=78.1 \%$, random effect) or those ranked with a low NOS score $(\mathrm{NOS} \leq 7, \mathrm{OR}=5.46,95 \% \mathrm{CI}=2.64,11.31, P=0.000$, $I^{2}=65.7 \%$, random effect). However, p-STAT3 expression was not obviously significant in studies with large sample size $(\mathrm{n}>100, \mathrm{OR}=5.78,95 \% \mathrm{CI}=0.56,59.51, P=0.140$, $I^{2}=65.2 \%$, random effect) or studies ranked as high quality (NOS $>7$, OR $=20.14,95 \% \mathrm{CI}=0.26,595.43, P<0.001$, $I^{2}=87.4 \%$, random effect). Heterogeneity was evident in each subgroup. Also, p-STAT3 expression was related to tumor differentiation in a subgroup of studies with a large sample size $\left(\mathrm{n}>100, \mathrm{OR}=1.78,95 \% \mathrm{CI}=1.15,3.69, P=0.015, I^{2}=0\right.$, random effect). However, p-STAT3 expression was not related to differentiation in other subgroups and heterogeneity was evident in the subgroups of studies with a small sample size and low NOS score subgroup (n $\leq 100, I^{2}=85 \%$ and NOS $\leq 7, I^{2}=82.8 \%$, respectively). Additionally, heterogeneity was significant for each TNM stage group. The sources of the heterogeneities could not be identified because of the limitations of sample size and NOS score. Despite this, p-STAT3 expression was related to poor clinicopathological features. It is conceivable that p-STAT3 plays an oncogenic role in $\mathrm{HCC}$.

\section{Association between p-STAT3 expression in HCC and 3- and 5-year OS and DFS}

Six studies comprising 610 patients were analyzed to determine the relationship between p-STAT3 expression and the 3-year OS (HR $=1.69,95 \%$ CI 1.07, 2.31; $I^{2}=0.0$, $P<0.001)$. Five studies comprising 542 patients were evaluated to establish the correlation between p-STAT3 and the 5-year OS (HR $=1.67,95 \%$ CI 1.18, 2.15; $\left.I^{2}=0.0, P<0.001\right)$. Three studies comprising 352 patients were examined to find the relationship between p-STAT3 expression and DFS $\left(\mathrm{HR}=1.94,95 \%\right.$ CI 1.42, 2.47; $\left.I^{2}=42.0 \%, P<0.001\right)$. These results (Figure 3 ) indicated that there is a correlation between the p-STAT3 expression and poor prognosis of patients with HCC. Additionally, these results reinforce the view that p-STAT3 may be a reliable prognostic biomarker for HCC.

\section{Publications bias}

No publication biases were evident for p-STAT3 expression $(P=0.06)$, gender $(P=0.711)$, age $(P=0.230)$, HBsAg 
Table I Characteristics of studies included in the meta-analysis

\begin{tabular}{|c|c|c|c|c|c|c|c|c|c|}
\hline Studies & Year & Country & Kind & $\begin{array}{l}\text { Number } \\
\text { of patients }\end{array}$ & $\begin{array}{l}\text { Laboratory } \\
\text { method }\end{array}$ & $\begin{array}{l}\text { Expression, } \\
\text { cancer }( \pm) \text { and } \\
\text { control }( \pm)\end{array}$ & $\begin{array}{l}\text { Gender, } \\
\text { male }( \pm) \text { and } \\
\text { female }( \pm)\end{array}$ & $\begin{array}{l}\text { Age (years), }>50 \\
( \pm) \text { and } \leq 50( \pm)\end{array}$ & $\begin{array}{l}\text { HBsAg, yes } \\
( \pm) \text { and no }( \pm)\end{array}$ \\
\hline \multirow[t]{2}{*}{ Yang et al ${ }^{16}$} & 2007 & Taiwan & $\mathrm{HCC}$ & 69 & $\mathrm{IHC}$ & $50 / 19$ & $38 / 14$ & NA & $30 / 12$ \\
\hline & & & & & & $14 / 55$ & $12 / 5$ & & $20 / 7$ \\
\hline \multirow[t]{2}{*}{ Wu et al ${ }^{12}$} & 2011 & China & $\mathrm{HCC}$ & 138 & $\mathrm{IHC}$ & $75 / 63$ & $60 / 55$ & $51 / 35$ & $60 / 51$ \\
\hline & & & & & & $35 / 75$ & $15 / 8$ & $24 / 28$ & $15 / 12$ \\
\hline \multirow[t]{2}{*}{ Wu et al ${ }^{22}$} & 2011 & China & $\mathrm{HCC}$ & 113 & $\mathrm{IHC}$ & NA & $55 / 37$ & $45 / 22$ & $58 / 34$ \\
\hline & & & & & & & $13 / 8$ & $23 / 23$ & $10 / 11$ \\
\hline \multirow{2}{*}{ Zhang et $\mathrm{al}^{1 / 4}$} & 2012 & China & $\mathrm{HCC}$ & 100 & $\mathrm{IHC}$ & $58 / 42$ & $48 / 32$ & $28 / 20$ & $47 / 38$ \\
\hline & & & & & & $0 / 10$ & $10 / 10$ & $30 / 22$ & $\mathrm{II} / 4$ \\
\hline \multirow[t]{2}{*}{ Zepeng et al ${ }^{19}$} & 2013 & China & $\mathrm{HCC}$ & 90 & $\mathrm{IHC}$ & $46 / 44$ & $35 / 30$ & $25 / 23$ & NA \\
\hline & & & & & & $0 / 90$ & $11 / 14$ & $21 / 21$ & \\
\hline \multirow[t]{2}{*}{ Mano et $\mathrm{al}^{15}$} & 2013 & Japan & $\mathrm{HCC}$ & 101 & $\mathrm{IHC}$ & NA & $26 / 55$ & NA & $8 / 14$ \\
\hline & & & & & & & $10 / 10$ & & $28 / 51$ \\
\hline \multirow[t]{2}{*}{ Tao et $\mathrm{al}^{20}$} & 2014 & China & $\mathrm{HCC}$ & 73 & $\mathrm{IHC}$ & $38 / 35$ & $31 / 30$ & NA & $32 / 26$ \\
\hline & & & & & & $20 / 53$ & $7 / 5$ & & $6 / 9$ \\
\hline \multirow[t]{2}{*}{ Lin et $\mathrm{a}^{21}$} & 2014 & China & $\mathrm{HCC}$ & 68 & $\mathrm{IHC}$ & $46 / 22$ & $38 / 18$ & $17 / 6$ & $41 / 18$ \\
\hline & & & & & & $18 / 50$ & $8 / 4$ & $29 / 16$ & $5 / 4$ \\
\hline
\end{tabular}

Abbreviations: AFP, alpha-fetoprotein; HBsAg, hepatitis B surface antigen; HCC, hepatocellular carcinoma; IHC, immunohistochemistry; DFS, disease-free survival; NA, not applicable; OS, overall survival.

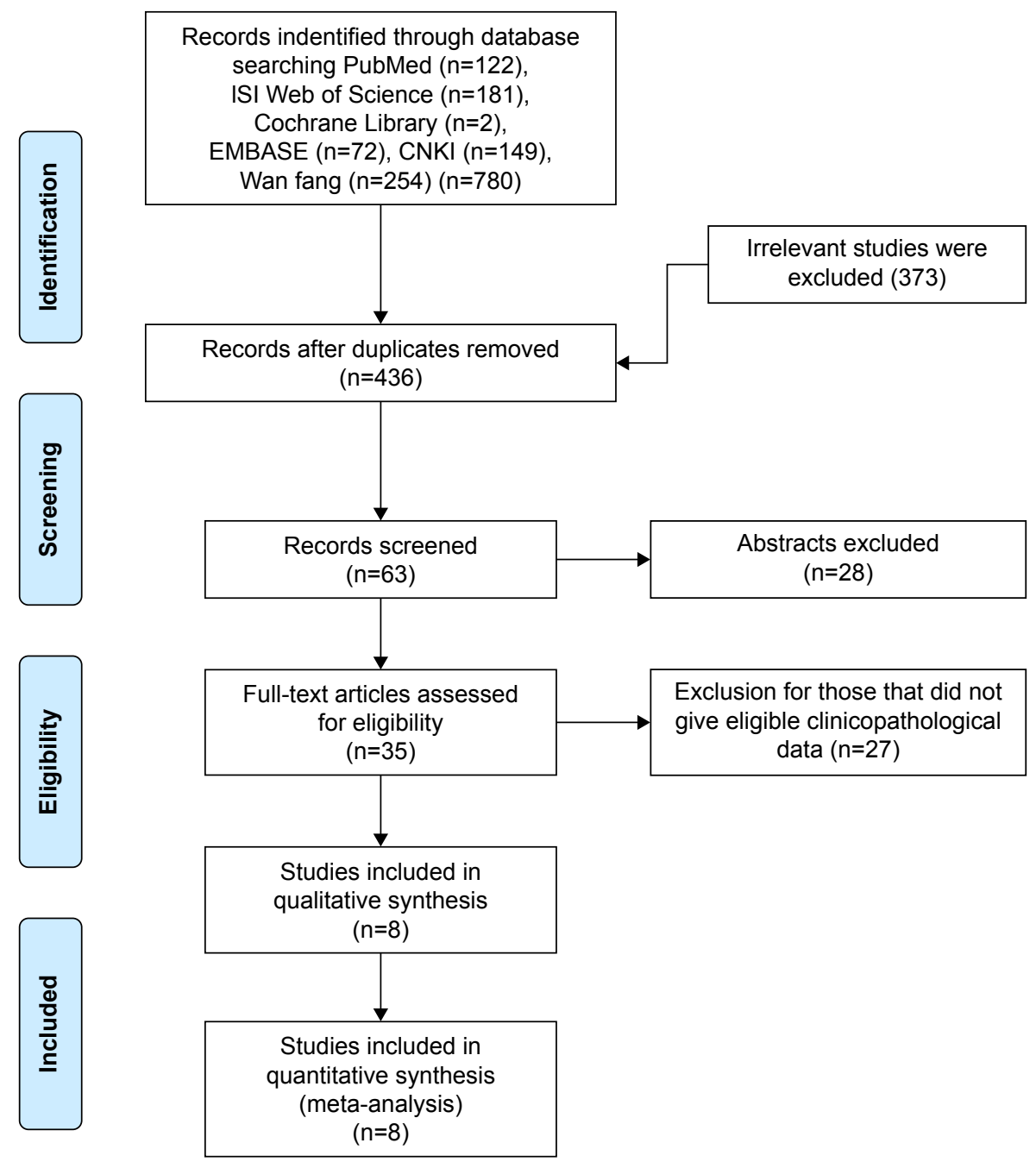

Figure I Flow diagram depicting the study selection. 


\begin{tabular}{|c|c|c|c|c|c|c|c|c|}
\hline $\begin{array}{l}\text { Liver cirrhosis, } \\
\text { yes }( \pm) \text { and } \\
\text { no }( \pm)\end{array}$ & $\begin{array}{l}\text { AFP, }>400 \\
( \pm) \text { and } \\
\leq 400( \pm)\end{array}$ & $\begin{array}{l}\text { Tumor size } \\
(\mathrm{cm}), \leq 5( \pm) \\
\text { and }>5( \pm)\end{array}$ & $\begin{array}{l}\text { Tumor number, } \\
\text { single }( \pm) \text { and } \\
\text { multiple }( \pm)\end{array}$ & $\begin{array}{l}\text { Vascular } \\
\text { invasion, yes }( \pm) \\
\text { and no }( \pm)\end{array}$ & $\begin{array}{l}\text { Differentiation, } \\
\text { low }( \pm) \text { and high } \\
\text { and moderate }( \pm)\end{array}$ & $\begin{array}{l}\text { TNM stage, } \\
\text { I, II ( } \pm \text { ) and } \\
\text { III, IV ( }( \pm)\end{array}$ & $\begin{array}{l}\text { Survival } \\
\text { information }\end{array}$ & $\begin{array}{l}\text { Quality } \\
\text { score }\end{array}$ \\
\hline $36 / 12$ & $25 / 8$ & $35 / 10$ & NA & $17 / 5$ & $3 / 5$ & $37 / 13$ & $\mathrm{~N}$ & 6 \\
\hline $14 / 7$ & $18 / 8$ & $15 / 9$ & & $33 / 14$ & $47 / 14$ & $13 / 6$ & & \\
\hline $69 / 56$ & NA & $13 / 28$ & NA & NA & $2 / 3$ & $50 / 56$ & OS RFS & 8 \\
\hline $6 / 7$ & & $62 / 35$ & & & $73 / 60$ & $25 / 7$ & & \\
\hline $63 / 38$ & NA & $17 / 15$ & NA & NA & $2 / 0$ & $47 / 39$ & OS DFS & 7 \\
\hline $5 / 7$ & & $51 / 30$ & & & $66 / 45$ & $21 / 6$ & & \\
\hline $38 / 22$ & $32 / 19$ & $29 / 26$ & NA & NA & $24 / 8$ & $35 / 25$ & OS & 8 \\
\hline $20 / 20$ & $26 / 23$ & $29 / 16$ & & & $34 / 34$ & $23 / 17$ & & \\
\hline \multirow[t]{2}{*}{ NA } & $36 / 27$ & $27 / 32$ & $29 / 32$ & $14 / \mid$ & $10 / 10$ & $24 / 40$ & OS & 8 \\
\hline & $10 / 17$ & $19 / 12$ & $17 / 12$ & $32 / 43$ & $36 / 34$ & $22 / 4$ & & \\
\hline $14 / 22$ & NA & NA & NA & $24 / 30$ & $16 / 19$ & NA & OS DFS & 8 \\
\hline $22 / 43$ & & & & $12 / 35$ & $20 / 46$ & & & \\
\hline \multirow[t]{2}{*}{ NA } & $12 / 14$ & $12 / 20$ & $28 / 39$ & $23 / 8$ & $11 / 3$ & $11 / 19$ & $\mathrm{~N}$ & 7 \\
\hline & $26 / 21$ & $26 / 15$ & $10 / 6$ & $15 / 27$ & $27 / 32$ & $27 / 16$ & & \\
\hline \multirow[t]{2}{*}{ NA } & $32 / 13$ & $18 / 10$ & $36 / 17$ & $31 / 8$ & $31 / 3$ & $16 / 17$ & OS & 7 \\
\hline & $14 / 9$ & $28 / 12$ & $10 / 5$ & $15 / 14$ & $15 / 19$ & $30 / 5$ & & \\
\hline
\end{tabular}

$(P=0.462)$, AFP $(P=1)$, liver cirrhosis $(P=0.806)$, tumor size $(P=0.707)$, number of tumors $(P=0.296)$, vascular invasion $(P=0.452)$, tumor differentiation $(P=0.368)$, TNM stage ( $P=0.230)$, 3-year OS $(P=0.268)$, 5-year OS $(P=0.368)$, and DFS ( $P=1)$ according to the Begg's test (Figures 3 and 4$)$.

\section{Discussion}

STAT3 becomes activated in response to interleukin-6 (IL-6) and other cytokines and functions as an acute-phase factor response factor. The STAT3 gene is located in human chromosome 17 . The 4815 bp gene harbors 24 exons that include STAT3 $\alpha, \beta$, and $\gamma \cdot{ }^{23,24}$ STAT3 is involved in early embryonic development and differentiation of bone marrow cells, regulation of cell growth and differentiation, proliferation, malignant transformation, and apoptosis inhibition, and other important physiological functions..$^{25-27}$

Recent experimental studies revealed the key role of STAT3 in the development of tumors. STAT3 is activated by a variety of carcinogens, including viral infections, ionizing radiation, growth factors, oncogenes, and inflammatory mediators. ${ }^{28}$ Constitutive activation of STAT3 occurs most often in tumor cells and generally does not occur in normal cells. p-STAT3 is overexpressed in a variety of tumor tissues and cells. Such overexpression is associated with clinicopathological features and prognosis of patients with various cancers, including HCC. However, the relationship

Table 2 p-STAT3 clinicopathological features for hepatocellular carcinoma

\begin{tabular}{|c|c|c|c|c|c|c|c|}
\hline \multicolumn{8}{|l|}{ Heterogeneity } \\
\hline $\begin{array}{l}\text { Clinicopathological } \\
\text { features }\end{array}$ & $\begin{array}{l}\text { Number } \\
\text { of studies }\end{array}$ & $\begin{array}{l}\text { Number } \\
\text { of patients }\end{array}$ & $\begin{array}{l}\text { Pooled OR } \\
(95 \% \mathrm{CI})\end{array}$ & PHet & $I^{2}(\%)$ & $P$-value & $\begin{array}{l}\text { Model } \\
\text { used }\end{array}$ \\
\hline Expression (positive:negative) & 6 & 958 & $6.27(2.85,13.79)$ & 0.001 & 76.5 & $<0.001$ & Random \\
\hline Gender (male:female) & 8 & 752 & $0.91(0.63, \mid .31)$ & 0.673 & 0.0 & 0.618 & Fixed \\
\hline Age (years) $(>50: \leq 50)$ & 5 & 509 & I.45 (1.01, I.49) & 0.704 & 0.0 & 0.044 & Fixed \\
\hline HBsAg (yes:no) & 7 & 662 & I.II $(0.75,1.65)$ & 0.568 & 0.0 & 0.597 & Fixed \\
\hline $\operatorname{AFP}(>400: \leq 400)$ & 5 & 390 & $1.40(0.92,2.14)$ & 0.529 & 0.0 & 0.121 & Fixed \\
\hline Liver cirrhosis (yes:no) & 5 & 521 & $1.56(1.01,2.43)$ & 0.942 & 0.0 & 0.046 & Fixed \\
\hline Tumor size $(\mathrm{cm})(\leq 5:>5)$ & 7 & 651 & $0.56(0.40,0.78)$ & 0.090 & 45.2 & 0.001 & Fixed \\
\hline Vascular invasion (yes:no) & 5 & 401 & $3.43(2.13,5.52)$ & 0.193 & 34.2 & $<0.001$ & Fixed \\
\hline Tumor number (single:multiple) & 3 & 231 & $0.64(0.35,1.18)$ & 0.568 & 0.0 & 0.155 & Fixed \\
\hline Differentiation (low:H + M) & 8 & 752 & I.8I $(0.79,4.15)$ & 0.002 & 69.3 & 0.161 & Random \\
\hline TNM stage (I + II:III + IV) & 7 & 651 & $0.36(0.19,0.70)$ & 0.007 & 66.1 & 0.003 & Random \\
\hline
\end{tabular}

Notes: Random, random-effects model; fixed, fixed-effects model; $\mathrm{H}+\mathrm{M}$, high + moderate level of differentiation.

Abbreviations: AFP, alpha-fetoprotein; $\mathrm{Cl}$, confidence interval; $\mathrm{HBsAg}$, hepatitis B surface antigen; OR, odds ratio; PHet, probability of hereogeneity. 


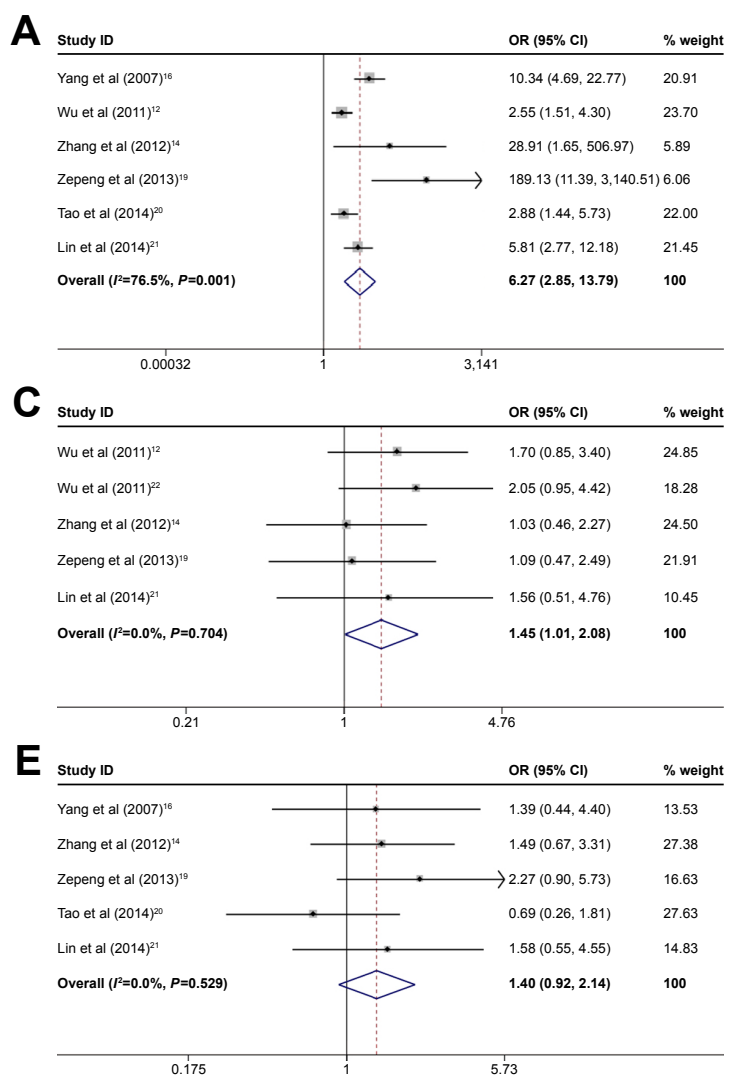

G Study ID $\quad$ OR (95\% Cl) \% weight

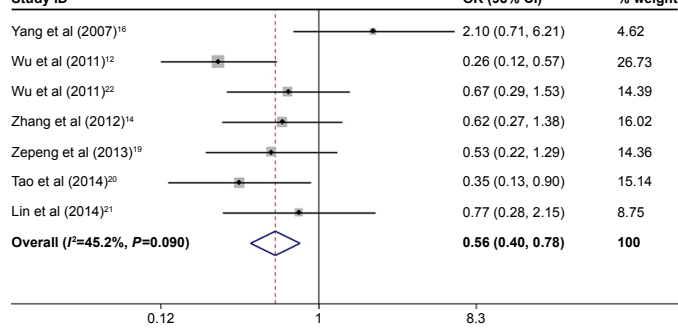

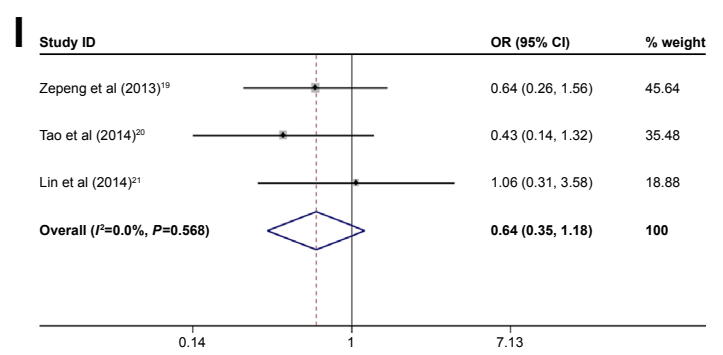

B

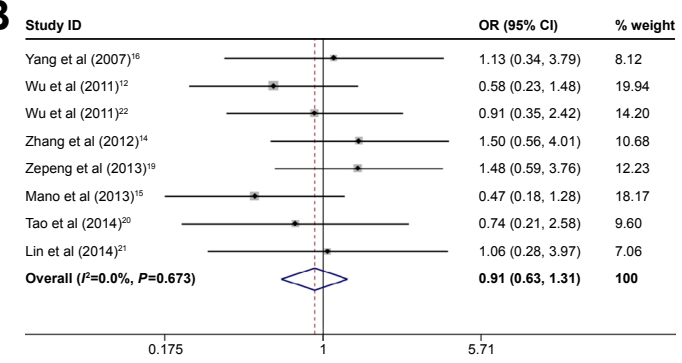

D study ID OR $(95 \% \mathrm{Cl}) \quad \%$ weight

Yang et al (2007) $)^{16}$ Wu et al $(2011)^{12}$ Wu et al $(2011)^{22}$ Zhang et al (2012) Mano et al (2013) Tao et al $(2014)^{20}$ Lin et al (2014) Overall $(R=0.0 \%, P=0.568)$

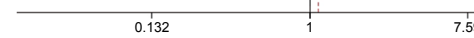

F study ID $0.88(0.29,2.60) \quad 14.77$ $0.94(0.40,2.19) \quad 23.54$ $0.94(0.40,2.19) \quad 23.54$ $1.88(0.72,4.88) \quad 12.78$ $0.45(0.13,1.53) \quad 17.75$ $1.04(0.39,2.78) \quad 16.48$ $\begin{array}{ll}1.04(0.39,2.78) & 16.48 \\ 1.85(0.58,5.86) & 9.07\end{array}$ $1.82(0.44,7.59) \quad 5.62$
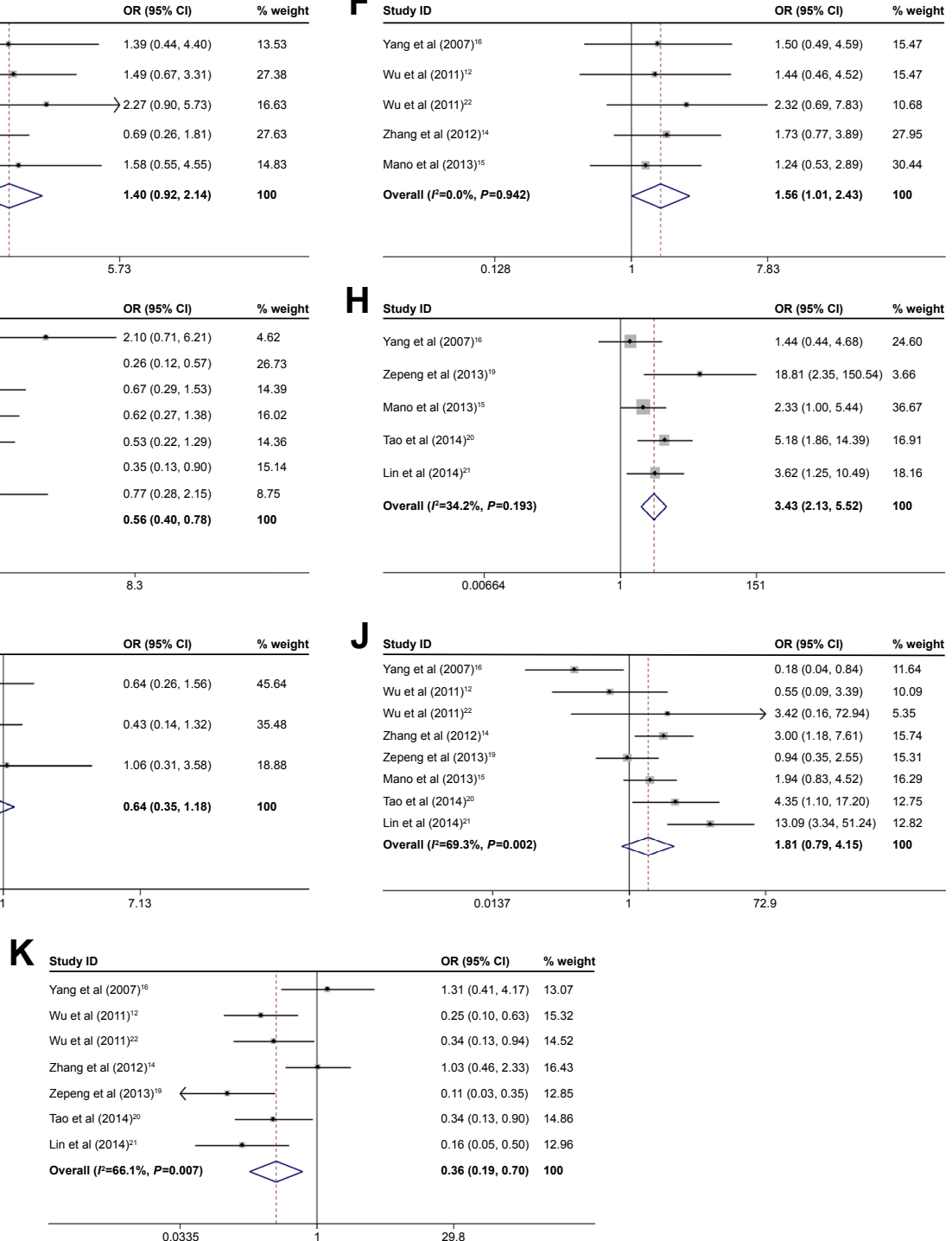

Figure 2 Forest plot of studies evaluating the association between p-STAT3 expression and clinicopathogical features including expression (A), gender (B), age (C), HBsAg (D), liver cirrhosis (E), AFP (F), tumor size (G), number of tumors $(\mathbf{H})$, vascular invasion (I), tumor differentiation (J), and TNM stage (K).

Note: Weights are from random-effects analysis.

Abbreviations: AFP, alpha-fetoprotein; HBsAg, hepatitis B surface antigen; OR, odds ratio. 
Table 3 Subgroup analysis of expression, differentiation, and TNM stage

\begin{tabular}{|c|c|c|c|c|c|c|}
\hline Subgroups & $\begin{array}{l}\text { Number } \\
\text { of studies }\end{array}$ & $\begin{array}{l}\text { Number } \\
\text { of patients }\end{array}$ & $\begin{array}{l}\text { Pooled OR } \\
(95 \% \mathrm{Cl})\end{array}$ & PHet & $I^{2}(\%)$ & $P$-value \\
\hline \multicolumn{7}{|l|}{ Expression } \\
\hline \multicolumn{7}{|l|}{ Sample size } \\
\hline$\leq 100$ & 4 & 600 & $7.70(2.82-21.00)$ & 0.003 & 78.1 & $<0.001$ \\
\hline$>100$ & 2 & 358 & $5.78(0.56-59.5 \mathrm{I})$ & 0.090 & 65.2 & 0.140 \\
\hline \multicolumn{7}{|l|}{ NOS score } \\
\hline$\leq 7$ & 3 & 153 & $5.46(2.64-\mid 1.31)$ & 0.054 & 65.7 & $<0.001$ \\
\hline$>7$ & 3 & 437 & $20.14(0.26-595.43)$ & $<0.001$ & 87.4 & 0.082 \\
\hline \multicolumn{7}{|c|}{ Differentiation } \\
\hline \multicolumn{7}{|l|}{ Sample size } \\
\hline$\leq 100$ & 4 & 300 & $1.78(0.33-9.54)$ & $<0.001$ & 85.0 & 0.500 \\
\hline$>100$ & 4 & 452 & $2.06(1.15-3.69)$ & 0.426 & 0.0 & 0.015 \\
\hline \multicolumn{7}{|l|}{ NOS score } \\
\hline$\leq 7$ & 4 & 323 & $2.4 \mid(0.32-18.17)$ & 0.001 & 82.8 & 0.393 \\
\hline$>7$ & 4 & 429 & $1.59(0.84-2.99)$ & 0.227 & 30.9 & 0.151 \\
\hline \multicolumn{7}{|l|}{ TNM stage } \\
\hline \multicolumn{7}{|l|}{ Sample size } \\
\hline$\leq 100$ & 3 & 300 & $0.30(0.11-0.84)$ & 0.016 & 71.1 & 0.022 \\
\hline$>100$ & 4 & 351 & $0.46(0.19-1.12)$ & 0.055 & 65.6 & 0.088 \\
\hline \multicolumn{7}{|l|}{ NOS score } \\
\hline$\leq 7$ & 4 & 323 & $0.39(0.18-0.87)$ & 0.082 & 55.3 & 0.021 \\
\hline$>7$ & 3 & 328 & $0.32(0.09-1.17)$ & 0.004 & 81.8 & 0.086 \\
\hline
\end{tabular}

Abbreviations: NOS, Newcastle-Ottawa Scale; OR, odds ratio; PHet, probability of hereogeneity.

between p-STAT3 expression and the clinicopathological features and prognosis of patients with $\mathrm{HCC}$ is unclear and contentious.

The current meta-analysis of eight studies comprising 752 HCC patients revealed the association of the expression of p-STAT3 with HCC incidence, age, liver cirrhosis, tumor size, vascular invasion, and TNM stage. These findings are evidence of the involvement of p-STAT3 in the development and progression of HCC. Furthermore, p-STAT3 expression was related to a poor 3- and 5-year OS rate as well as the DFS rate, suggesting that $\mathrm{p}$-STAT3 could be a reliable biomarker for the prognosis of patients with HCC.

STAT3 appears to be involved in the tumor inflammatory response, tumor cell transformation, survival, proliferation, angiogenesis, invasion, and metastasis. For instance, Miyatsuka et $\mathrm{al}^{29}$ suggested that the activation of STAT3 in pancreatic cells upregulates the expression of pancreaticduodenal homeobox 1 (PDX1), leading to the transformation of pancreatic acinar cells to ductal cells, which is the basis of pancreatic cancer. Their results suggested that activation of STAT3 promotes tumor cell transformation. Also, Fan et a $l^{30}$ reported that the expressions of the proapoptotic factors BCL2L1 and BIRC5 were downregulated when STAT3 expression was downregulated in colon cancer cells. Li et al ${ }^{31}$ found that silencing STAT3 can significantly downregulate BCL2 and lead to increased glioma cell apoptosis, suggesting that STAT3 can protect tumor cells from apoptosis. Masuda et $\mathrm{al}^{32}$ showed that p-STAT3 inhibits the expression of cyclin D1, which contributes to the proliferation of head and neck squamous cell carcinoma. In addition, p-STAT3 expression has been positively correlated to cyclin D1 expression, while the activation of epidermal growth factor receptor in glioma cells can cause excessive activation of STAT3, and the resulting increased expression of cyclin D1 drives the accelerated proliferation of tumor cells. ${ }^{33}$ Moreover, STAT3 was found to promote invasion and metastasis of tumor cells by upregulating matrix metalloproteinases (MMP1, MMP2 and MMP9) and overexpression of p-STAT3 was closely related to tumor angiogenesis. ${ }^{22,34}$ Furthermore, p-STAT3 participates in the interaction between tumor cells and the immune system, which leads to the inhibition of the release of some inflammatory mediators, such as tumor necrosis factor (TNF) and nitric oxide (NO), which in turn contributes to a weakened inflammatory response and promotion of the escape of tumor cells from T-cell-mediated killing. ${ }^{35,36}$

This meta-analysis confirms that p-STAT3 is associated with clinicopathological features and may be a specific biomarker for the prognosis of patients with HCC. Nevertheless, these conclusions must remain tentative due to the many limitations of this meta-analysis. First, most of the included studies were conducted in China, so the results may not be generalizable to non-Chinese or non-Asian individuals. More 
A

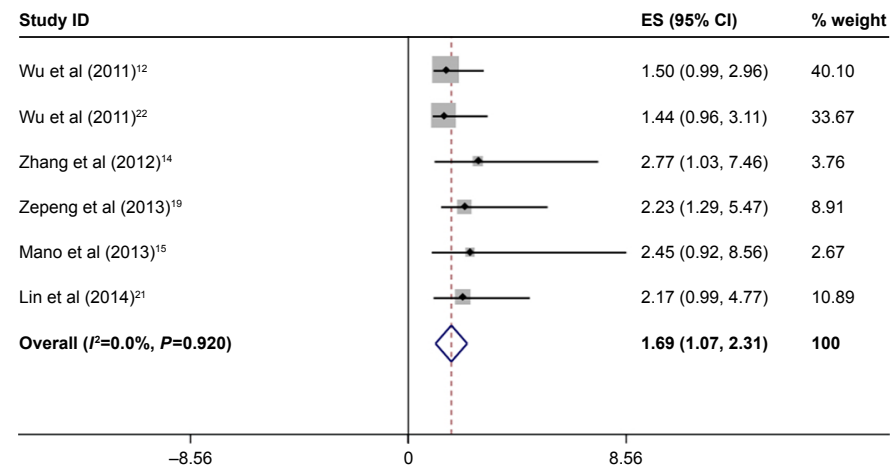

B

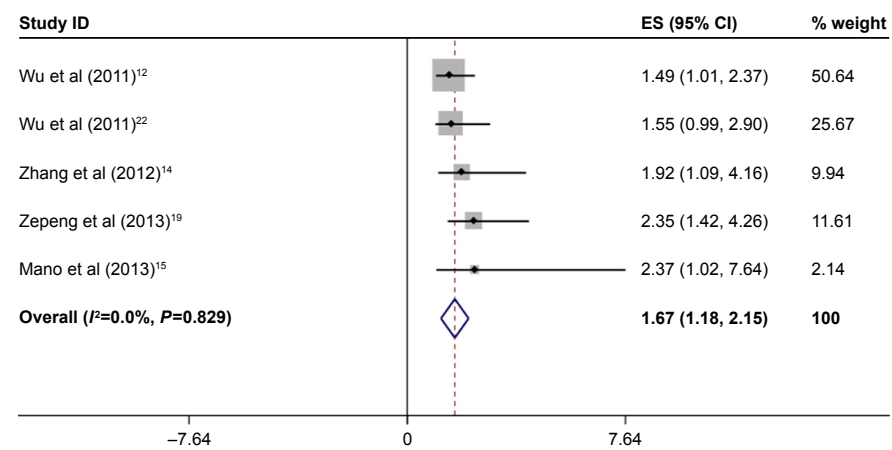

C

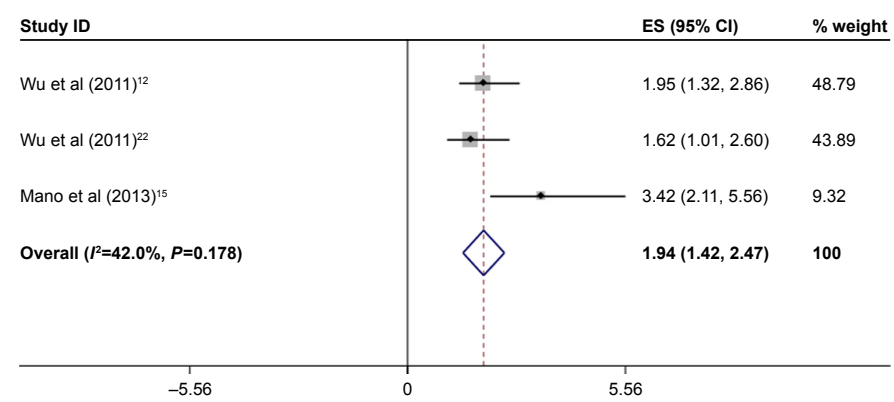

\section{Begg's funnel plot with pseudo $95 \%$ confidence limits}

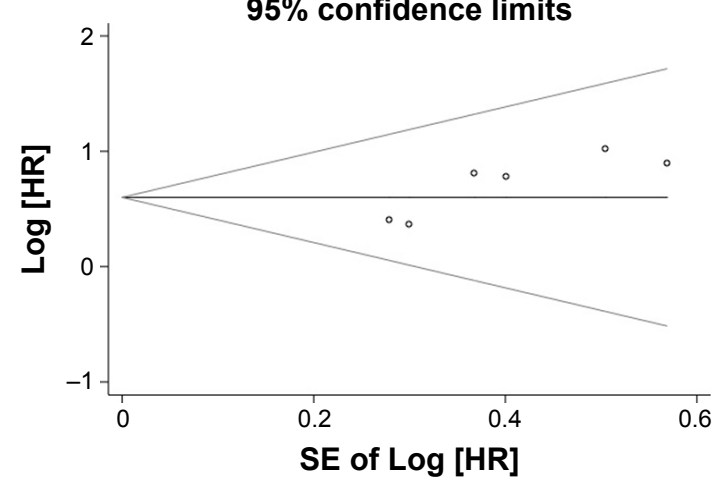

E Begg's funnel plot with pseudo

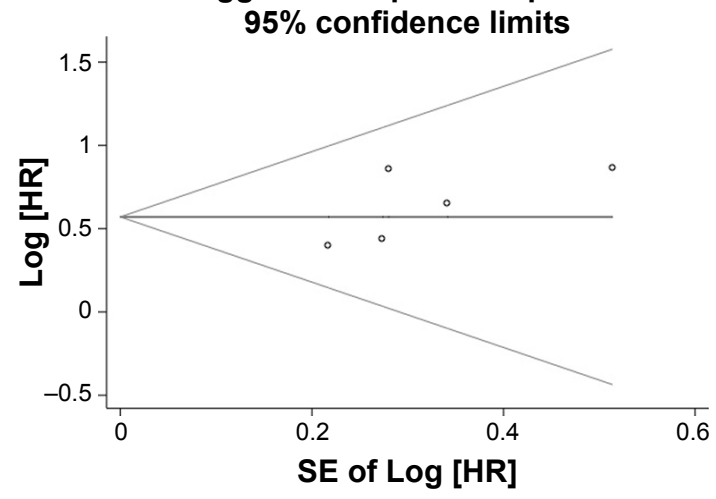

F Begg's funnel plot with pseudo 95\% confidence limits

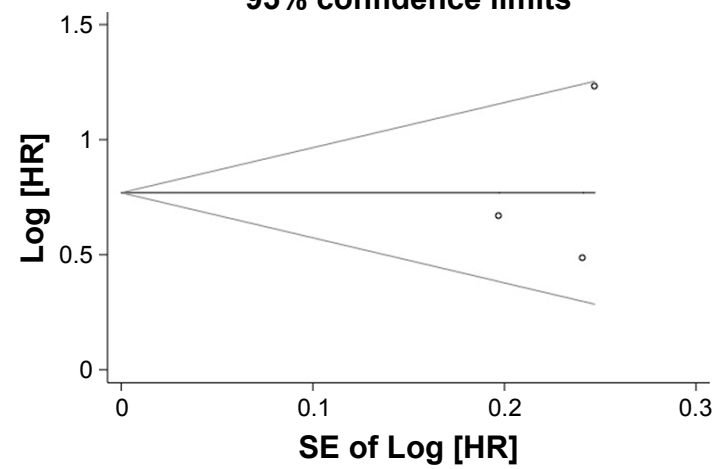

Figure 3 Pooled analysis for the association between P-STAT3 expression and the 3-year OS rate (A: Forest plot, D: Begg's publication bias plot), the 5-year OS rate (B: Forest plot, E: Begg's publication bias plot), and the DFS rate (C: Forest plot, F: Begg's publication bias plot).

Abbreviations: DFS, disease-free survival; HR, hazard ratio; OS, overall survival.

studies will be needed to confirm or refute the present findings in other races and ethnicities. Second, although subgroups' analysis involved sample size and NOS score, there was heterogeneity present and the source of such heterogeneity was unclear. A possible explanation is the experimental methods used in the included studies. For instance, IHC analysis, which was used in all studies, is a semiquantitative research method that can be influenced by the use of different antibodies and cutoff values. Careful inspection of the articles determined that the source of the p-STAT3 antibody differed between some of the studies (some purchased from Santa Cruz Biotechnology Inc., Dallas, TX, USA, and others from Cell Signaling Technology CST, Danvers, MA, USA). Furthermore, the antibody dilutions used in the IHC procedures were different (1:200, 1:150, 1:100, and 1:50 in the studies that reported the dilution). Additionally, the positive cutoff values differed $(19 \%, 25 \%$, or $50 \%)$. These differences likely influenced the outcome of the decisions. High-quality studies 
involving large numbers of individuals that utilize the same antibody, antibody dilution, and cutoff value are needed to further support the present findings. Finally, HRs were obtained using the Engauge Digitizer 10.0 software, which may have caused some offset.

A
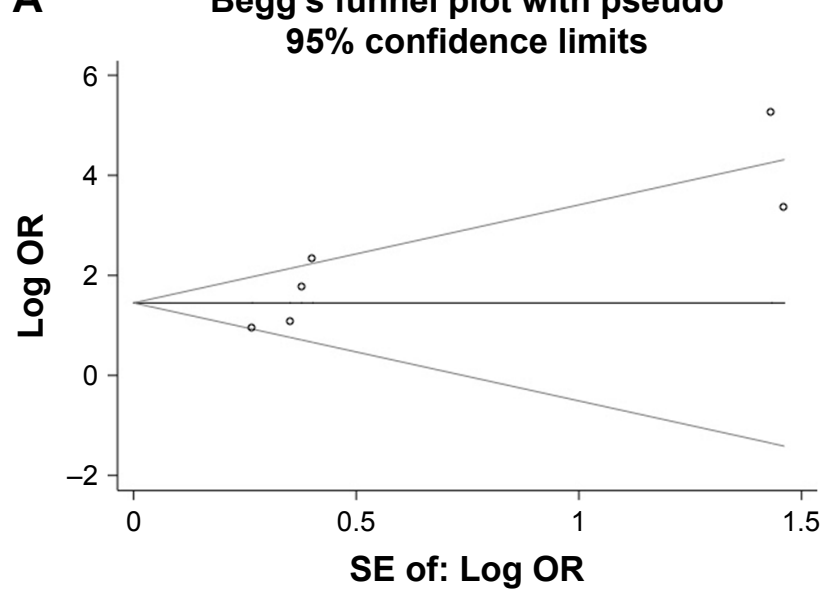

C Begg's funnel plot with pseudo

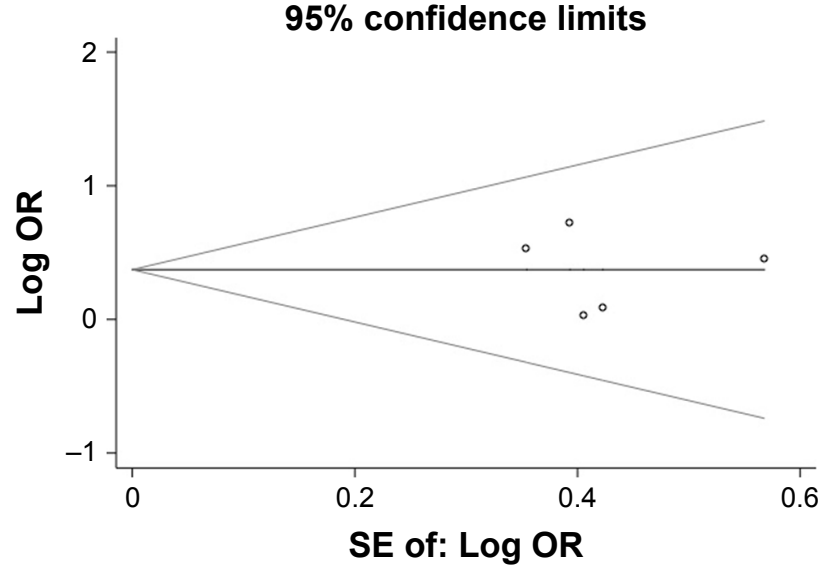

E Begg's funnel plot with pseudo

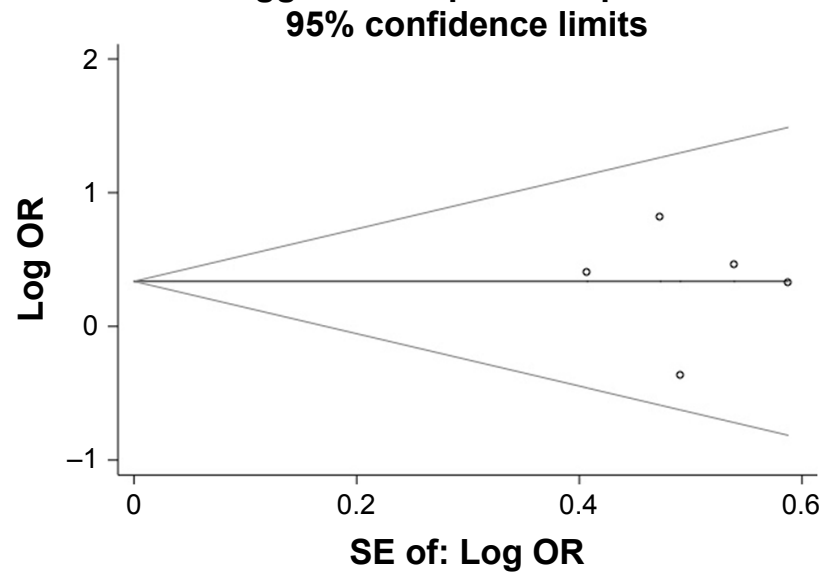

\section{Conclusion}

Despite the limitations, the results are still significant. The expression of p-STAT3 was associated with HCC incidence, as well as age, liver cirrhosis, tumor size, vascular invasion, and TNM stage in patients with HCC. Additionally,

\section{B Begg's funnel plot with pseudo 95\% confidence limits}
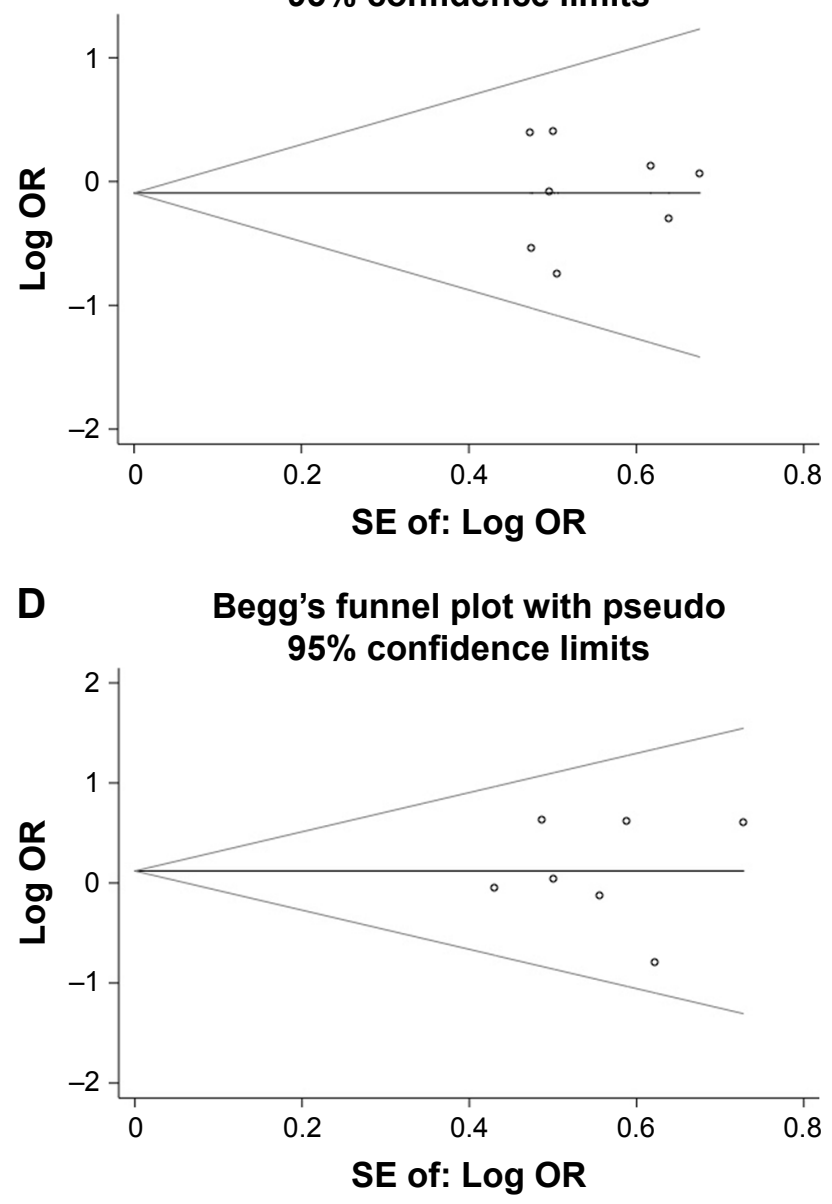

F Begg's funnel plot with pseudo

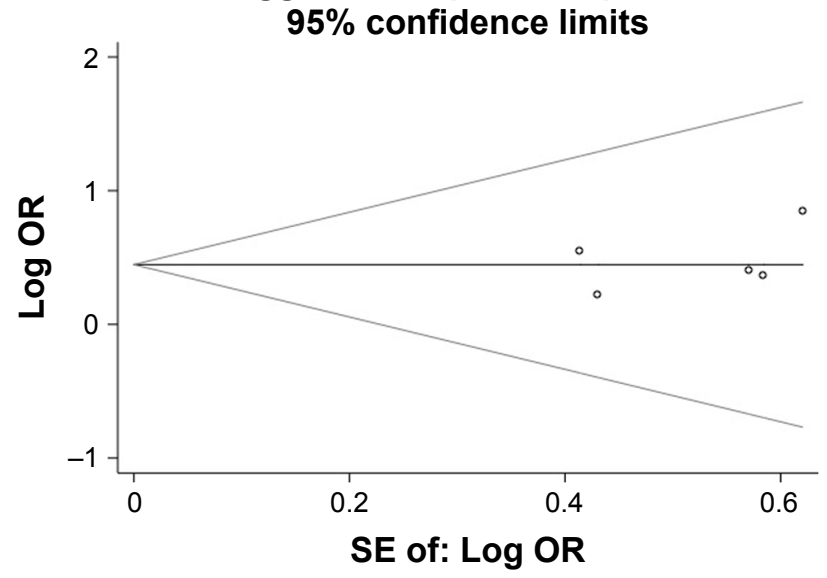

Figure 4 (Continued) 
G

Begg's funnel plot with pseudo $95 \%$ confidence limits

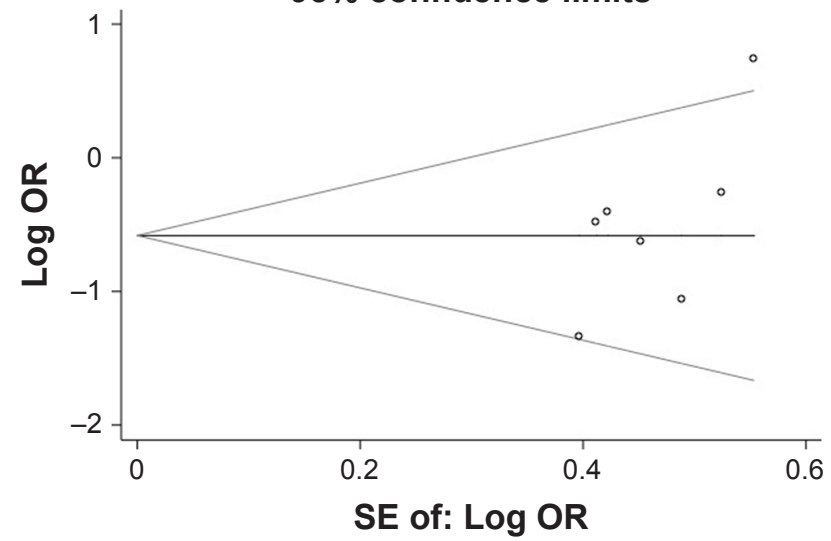

I

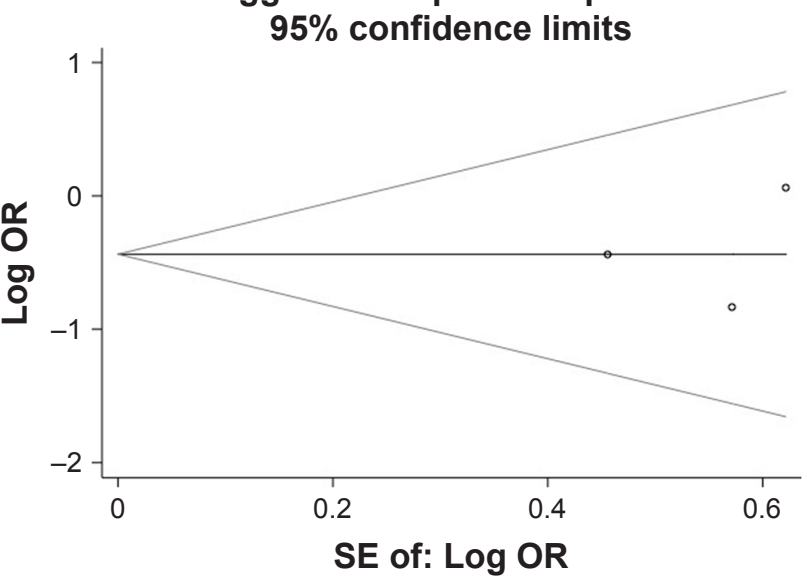

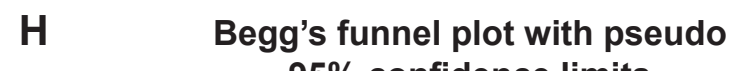

$95 \%$ confidence limits

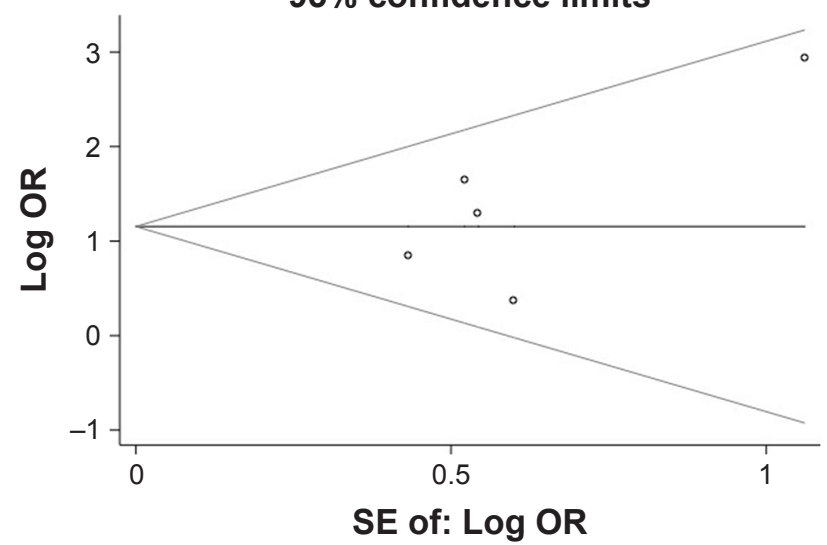

$\mathbf{J}$

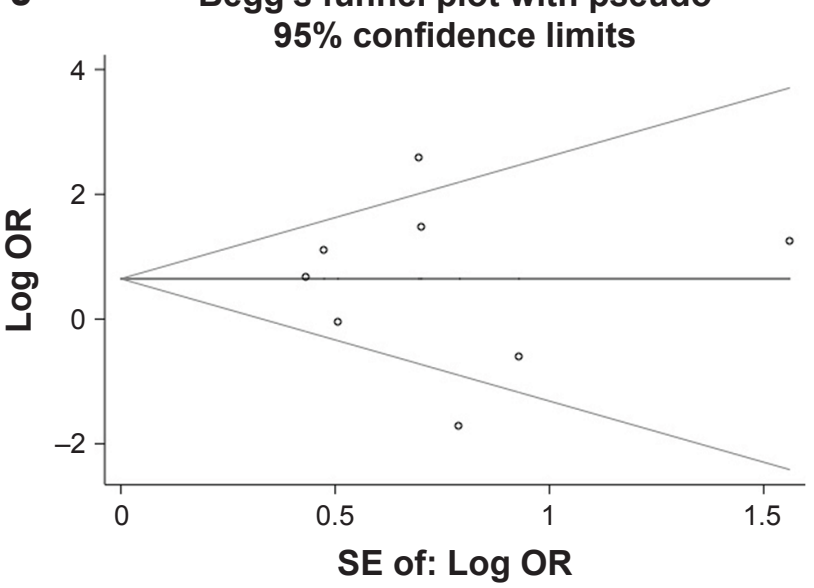

K Begg's funnel plot with pseudo

$95 \%$ confidence limits

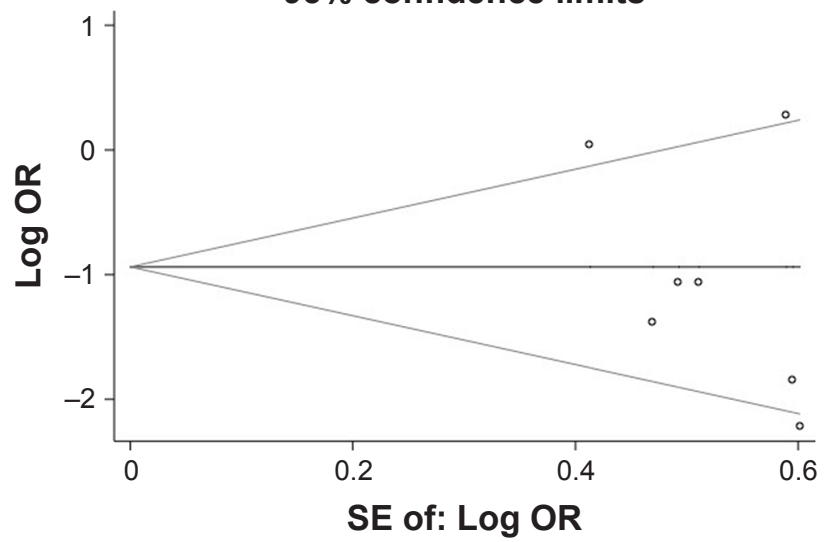

Figure 4 Begg's publication bias plot for the p-STAT3-related studies including expression (A), gender (B), age (C), HBsAg (D), liver cirrhosis (E), AFP (F), tumor size (G), number of tumors $(\mathbf{H})$, vascular invasion (I), differentiation $(\mathbf{J})$, and TNM stage $(\mathbf{K})$.

Abbreviations: AFP, alpha-fetoprotein; $\mathrm{HBsAg}$, hepatitis $B$ surface antigen; OR, odds ratio.

p-STAT3 expression correlated with poor 3- and 5-year OS and DFS. The collective findings implicate p-STAT3 as a reliable biomarker for the prognosis of patients with $\mathrm{HCC}$, pending the results of high-quality studies involving larger numbers of individuals.

\section{Acknowledgments}

This study was funded by Beijing Municipal Administration of Hospital Clinical Medicine Development of Special Funding Support (ZYLX201612), the Capital Foundation of Medical Development (shoufa2016-2-2053), and the Municipal 
Administration of Hospital Clinical Medicine Development of Special Funding Support (trzdyxzy201705).

\section{Disclosure}

The authors report no conflicts of interest in this work.

\section{References}

1. Siegel R, Naishadham D, Jemal A. Cancer statistics, 2012. CA Cancer J Clin. 2012;62(1):10-29.

2. Chen W, Zheng R, Baade PD, et al. Cancer statistics in China, 2015. CA Cancer J Clin. 2016;66(2):115-132.

3. Forner A, Llovet JM, Bruix J. Hepatocellular carcinoma. Lancet. 2012;379(9822):1245-1255.

4. Avila MA, Berasain C, Sangro B, Prieto J. New therapies for hepatocellular carcinoma. Oncogene. 2006;25(27):3866-3884.

5. Nishikawa H, Kimura T, Kita R, Osaki Y. Treatment for hepatocellular carcinoma in elderly patients: a literature review. J Cancer. 2013;4(8): 635-643.

6. Gamero AM, Young HA, Wiltrout RH. Inactivation of Stat3 in tumor cells: releasing a brake on immune responses against cancer? Cancer Cell. 2004;5(2):111-112.

7. Jia Y, Liu D, Xiao D, et al. Expression of AFP and STAT3 is involved in arsenic trioxide-induced apoptosis and inhibition of proliferation in AFP-producing gastric cancer cells. PLoS One. 2013;8(1):e54774.

8. Denley SM, Jamieson NB, McCall P, et al. Activation of the IL-6R/Jak/ stat pathway is associated with a poor outcome in resected pancreatic ductal adenocarcinoma. J Gastrointest Surg. 2013;17(5):887-898.

9. Tam L, McGlynn LM, Traynor P, Mukherjee R, Bartlett JM, Edwards J. Expression levels of the JAK/STAT pathway in the transition from hormone-sensitive to hormone-refractory prostate cancer. Br J Cancer. 2007;97(3):378-383.

10. Sonnenblick A, Uziely B, Nechushtan H, et al. Tumor STAT3 tyrosine phosphorylation status, as a predictor of benefit from adjuvant chemotherapy for breast cancer. Breast Cancer Res Treat. 2013;138(2): 407-413.

11. Kusaba T, Nakayama T, Yamazumi K, et al. Activation of STAT3 is a marker of poor prognosis in human colorectal cancer. Oncol Rep. 2006;15(6):1445-1451.

12. Wu ZS, Cheng XW, Wang XN, Song NJ. Prognostic significance of phosphorylated signal transducer and activator of transcription 3 and suppressor of cytokine signaling 3 expression in human cutaneous melanoma. Melanoma Res. 2011;21(6):483-490.

13. Wu WY, Li J, Wu ZS, Zhang CL, Meng XL, Lobie PE. Prognostic significance of phosphorylated signal transducer and activator of transcription 3 and suppressor of cytokine signaling 3 expression in hepatocellular carcinoma. Exp Ther Med. 2011;2(4):647-653.

14. Zhang $\mathrm{CH}, \mathrm{Xu}$ GL, Jia WD, et al. Activation of STAT3 signal pathway correlates with twist and E-cadherin expression in hepatocellular carcinoma and their clinical significance. J Surg Res. 2012;174(1): $120-129$.

15. Mano Y, Aishima S, Fujita N, et al. Tumor-associated macrophage promotes tumor progression via STAT3 signaling in hepatocellular carcinoma. Pathobiology. 2013;80(3):146-154.

16. Yang SF, Wang SN, Wu CF, et al. Altered p-STAT3 (tyr705) expression is associated with histological grading and intratumour microvessel density in hepatocellular carcinoma. J Clin Pathol. 2007;60(6):642-648.

17. Wu P, Wu D, Zhao L, et al. Prognostic role of STAT3 in solid tumors: a systematic review and meta-analysis. Oncotarget. 2016;7(15): 19863-19883.
18. Li MX, Bi XY, Huang Z, et al. Prognostic role of phospho-STAT3 in patients with cancers of the digestive system: a systematic review and meta-analysis. PLoS One. 2015;10(5):e0127356.

19. Zepeng G, Desheng W, Liang Z, et al. STAT3 expression profile and its clinical significance in hepatocellular carcinoma. J Clin Hepatol. 2013;29:520-524.

20. Tao S, Xue Y, Cheng G, et al. Expression of STAT3 and p-STAT3 in human hepatocellular carcinoma and its relationship with clinicopathological characteristics. J Xi'an Jiaotong Univ. 2014;35:81-84.

21. Lin W, Tao S, Yan-Li W, Zhi-Kui L, Xue Y, Zhi-min G. Expression and clinical significance of p-STAT3 in hepatocelluar carcinoma. J Hepatocel Carcinoma. 2014;1:40-43.

22. Wu WY, Li J, Wu ZS, Zhang CL, Meng XL. STAT3 activation in monocytes accelerates liver cancer progression. BMC Cancer. 2011; 11:506.

23. Yu H, Pardoll D, Jove R. STATs in cancer inflammation and immunity: a leading role for STAT3. Nat Rev Cancer. 2009;9(11):798-809.

24. Ernst M, Najdovska M, Grail D, et al. STAT3 and STAT1 mediate IL-11-dependent and inflammation-associated gastric tumorigenesis in gp130 receptor mutant mice. J Clin Invest. 2008;118(5): 1727-1738.

25. Bollrath J, Phesse TJ, von Burstin VA, et al. gp130-mediated Stat3 activation in enterocytes regulates cell survival and cell-cycle progression during colitis-associated tumorigenesis. Cancer Cell. 2009;15(2): 91-102.

26. Stark GR, Darnell JE Jr. The JAK-STAT pathway at twenty. Immunity. 2012;36(4):503-514.

27. Raz R, Lee CK, Cannizzaro LA, d'Eustachio P, Levy DE. Essential role of STAT3 for embryonic stem cell pluripotency. Proc Natl Acad Sci U S A. 1999;96(6):2846-2851.

28. Aggarwal BB, Gehlot P. Inflammation and cancer: how friendly is the relationship for cancer patients? Curr Opin Pharmacol. 2009;9(4): 351-369.

29. Miyatsuka T, Kaneto H, Shiraiwa T, et al. Persistent expression of PDX-1 in the pancreas causes acinar-to-ductal metaplasia through Stat3 activation. Genes Dev. 2006;20(11):1435-1440.

30. Fan Y, Zhang YL, Wu Y, et al. Inhibition of signal transducer and activator of transcription 3 expression by RNA interference suppresses invasion through inducing anoikis in human colon cancer cells. World J Gastroenterol. 2008;14(3):428-434.

31. Li GH, Wei H, Lv SQ, Ji H, Wang DL. Knockdown of STAT3 expression by RNAi suppresses growth and induces apoptosis and differentiation in glioblastoma stem cells. Int J Oncol. 2010;37(1):103-110.

32. Masuda M, Suzui M, Yasumatu R, et al. Constitutive activation of signal transducers and activators of transcription 3 correlates with cyclin D1 overexpression and may provide a novel prognostic marker in head and neck squamous cell carcinoma. Cancer Res. 2002;62(12): 3351-3355.

33. Wheeler SE, Suzuki S, Thomas SM, et al. Epidermal growth factor receptor variant III mediates head and neck cancer cell invasion via STAT3 activation. Oncogene. 2010;29(37):5135-5145.

34. Shi M, Liu D, Duan H, et al. Catecholamine up-regulates MMP-7 expression by activating AP-1 and STAT3 in gastric cancer. $\mathrm{Mol}$ Cancer. 2010;9:269.

35. Rivat C, Rodrigues S, Bruyneel E, et al. Implication of STAT3 signaling in human colonic cancer cells during intestinal trefoil factor 3 (TFF3) and vascular endothelial growth factor-mediated cellular invasion and tumor growth. Cancer Res. 2005;65(1):195-202.

36. Oh HM, Yu CR, Golestaneh N, et al. STAT3 protein promotes T-cell survival and inhibits interleukin-2 production through up-regulation of Class O Forkhead transcription factors. J Biol Chem. 2011;286(35): 30888-30897. 


\section{Publish your work in this journal}

OncoTargets and Therapy is an international, peer-reviewed, open access journal focusing on the pathological basis of all cancers, potential targets for therapy and treatment protocols employed to improve the management of cancer patients. The journal also focuses on the impact of management programs and new therapeutic agents and protocols on

patient perspectives such as quality of life, adherence and satisfaction. The manuscript management system is completely online and includes a very quick and fair peer-review system, which is all easy to use. Visit http://www.dovepress.com/testimonials.php to read real quotes from published authors.

Submit your manuscript here: http://www.dovepress.com/oncotargets-and-therapy-journal 